|| ISSN(online): 2589-8698 || ISSN(print): 2589-868X || International Journal of Medical and Biomedical Studies

Available Online at www.ijmbs.info

PubMed (National Library of Medicine ID: 101738825)

Index Copernicus Value 2018: 75.71

Volume 3, Issue 4; April: 2019; Page No. 154-158

\title{
FASTING LIPID PROFILE AND DISEASE SEVERITY IN SEPSIS PATIENTS
}

\author{
Pramod Sood ${ }^{1}$, Manpreet Kaur ${ }^{2}$ \\ ${ }^{1}$ Associate Professor, Department of Critical Care Medicine, Dayanand Medical College and Hospital \\ Ludhiana \\ ${ }^{2}$ Reader, Department of oral pathology, Pacific dental College Udaipur.
}

Article Info: Received 25 March 2019; Accepted 20 April. 2019

Cite this article as: Sood, P., \& Kaur, M. (2019). FASTING LIPID PROFILE AND DISEASE SEVERITY IN SEPSIS PATIENTS. International Journal of Medical and Biomedical Studies, 3(4).

DOI: https://doi.org/10.32553/ijmbs.v3i4.207

Address for Correspondence: Pramod Sood, Associate Professor, Department of Critical Care Medicine, Dayanand Medical College and Hospital Ludhiana

Conflict of interest: No conflict of interest.

\section{Abstract}

Background: During an infection and inflammation many cytokines are released. This produces many changes in plasma lipids and lipoprotein concentration.

Methods: This was a prospective observational study. Patients with age greater than 18 years and satisfying the criteria for sepsis according to International guidelines for management of severe sepsis and septic shock 2016 were included.

Results: The study population comprised 16 males and 14 females with mean age of $57.2 \pm 7.21$ years. Both groups were comparable. Cholesterol, HDL and LDL level difference in septic and control was stastically significant.

Conclusion: In ICU setting, measurement of cholesterol values has been shown to improve risk prediction, and inclusion of lipid values in clinical risk assessment scores of critically ill patients has been advocated.

Keywords: Lipid profile, Sepsis, Cholesterol.

\section{Introduction}

Sepsis is a significant public health concern. ${ }^{1}$ Sepsis affects persons of all ages is the leading cause of morbidity and mortality for patients admitted to an intensive care unit (ICU) and may be considered the tenth leading cause of death overall in the United States. The incidence of sepsis is projected to increase by $1.5 \%$ per year, rising to more than $1,110,000$ cases or more annually by $2020 .^{2}$ The incidence of severe sepsis in India was $16.45 \%$ of all 5478 total admissions. Mean age of the population was 58.17 years of which $57.71 \%$ were male.
During an infection and inflammation many cytokines are released. This produces many changes in plasma lipids and lipoprotein concentration $^{3}$. In patients with infection, decrease in serum levels of total cholesterol, LDL and HDL and increase of serum triglyceride have been reported in most studies ${ }^{4}$. These changes were independent of the underlying disease or infectious agents ${ }^{5}$. It has been proposed that these changes induce anti-inflammatory effects that contribute to host defense ${ }^{6}$ It is not clear whether these changes in plasma lipids will help in identifying inflammation due to the infection ${ }^{7}$. There are many studies showing the relationship between low cholesterol and sepsis. In patients 
who develop severe sepsis, the total and HDL cholesterol level fell and reached $50 \%$ of recovery levels by the third day ${ }^{8}$. These changes in lipids in sepsis may help in predicting the prognosis and may have a therapeutic role also. This study was conducted to assess lipid profile abnormalities in patients with sepsis: sepsis, severe sepsis and septic shock and to study the relationship between fasting lipid profile and disease severity and mortality in patients with sepsis and the usefulness of lipids as a prognostic indicator in patients with sepsis.

\section{Material and Methods}

This was a prospective observational study.

Inclusion criteria Patients with age greater than 18 years and satisfying the criteria for sepsis according to International guidelines for management of severe sepsis and septic shock 2016. $^{4}$

\section{Exclusion criteria}

- Patients on treatment with statins,

- Patients with chronic kidney disease, chronic liver disease, thyroid dysfunction, diabetes mellitus and mal-absorbption disorders,

- Patients with known chronic infective and inflammatory conditions like Human immunodeficiency virus disease, SLE (Systemic lupus erythematous) and RA (Rheumatoid arthritis).

After getting written informed consent from the patients or immediate relatives, the selected patients were examined in detail. Their vital signs like pulse, blood pressure, respiratory rate, temperature were checked. We looked for pallor, cyanosis, clubbing, icterus, oedema, generalised lymphadenopathy, skin infections and any other focus of infection. A detailed clinical examination of respiratory system, cardiovascular system, gastrointestinal system and nervous system was done in all patients. Laboratory investigations included complete haemogram, urine routine examination, blood sugar, renal function tests, liver function tests, culture of blood, urine, and sputum, chest X-ray, ECG, Echocardiography and serological tests like IgM leptospiral antibody, IgM dengue antibody, WIDAL test, Arterial blood gas analysis etc. Diagnosis of sepsis was made in patients who satisfied the ACCP/SCCM criteria. Patients were categorised into subgroups according to severity of sepsis as sepsis, severe sepsis and septic shock. Their fasting lipid profiles were measured on the next day morning. The development of complications like renal failure and the need for dialysis, pulmonary complications like Acute Lung Injury and Acute Respiratory Distress Syndrome (ALI/ARDS), need for ventilator support, hypotension and need for ionotropes and development of multiorgan failure and death were noted.

Serum total cholesterol was determined using CHOD-POD (cholesterol oxidase-peroxidase) method and triglyerides by enzymatic method using lipoprotein lipase, glycerol kinase, glycerol phosphate oxidase and peroxidase. HDL cholesterol measured using separation by precipitation with phosphotungstic acid and magnesium chloride. LDL cholesterol was calculated according to the formula, LDL-C= Total cholesterol- TGL/5-HDL.

\section{Statistical Method}

Statistical analysis was carried out using EPI-Info software. Microsoft Word and Excel have been used to generate graphs, tables etc. Results on continuous measurements are presented on Mean \pm SD (Min-Max) and results on categorical measurements are presented in number (\%). Significance is assessed at $5 \%$ level of significance. Chi-square/ Fisher Exact test has been used to find the significance of study parameters on categorical scale between two or more groups. P-value $<0.05$ was consider significant.

\section{RESULTS}


Table 1: socio-demographic variable

\begin{tabular}{|l|l|l|}
\hline Socio-demographic & Sepsis group $(n=30)$ & Control group $(n=30)$ \\
\hline Age (Mean \pm SD) & $57.2 \pm 7.21$ & $59.35 \pm 8.56$ \\
\hline Male : Female & $16: 14$ & $17: 13$ \\
\hline Rural : Urban & $19: 11$ & $18: 12$ \\
\hline
\end{tabular}

The study population comprised 16 males and 14 females with mean age of $57.2 \pm 7.21$ years. Both groups were comparable.

Table 2: Association between lipid profile levels and outcome

\begin{tabular}{|l|l|l|l|}
\hline \multicolumn{2}{|l|}{ Lipid profile } & Discharge $(\mathrm{n}=23)$ & Dead $(\mathrm{n}=7)$ \\
\hline \multirow{2}{*}{ Cholesterol } & $<200 \mathrm{mg} / \mathrm{dL}$ & $20(86.96 \%)$ & $6(85.71 \%)$ \\
\cline { 2 - 4 } & $>200 \mathrm{mg} / \mathrm{dL}$ & $3(13.04 \%)$ & $1(14.29 \%)$ \\
\hline \multirow{3}{*}{ Triglyceride } & $<150 \mathrm{mg} / \mathrm{d}$ & $16(69.56 \%)$ & $4(57.14 \%)$ \\
\cline { 2 - 4 } & $>150 \mathrm{mg} / \mathrm{d}$ & $7(30.44 \%)$ & $3(42.86 \%)$ \\
\hline \multirow{3}{*}{$\mathrm{HDL}$} & $<50 \mathrm{mg} / \mathrm{dL}$ & $18(78.26 \%)$ & $5(71.42 \%)$ \\
\cline { 2 - 4 } & $>50 \mathrm{mg} / \mathrm{dL}$ & $5(21.74 \%)$ & $2(28.57 \%)$ \\
\hline \multirow{2}{*}{ LDL } & $<100 \mathrm{mg} / \mathrm{dL}$ & $17(73.91 \%)$ & $4(57.14 \%)$ \\
\cline { 2 - 4 } & $>100 \mathrm{mg} / \mathrm{dL}$ & $6(26.09 \%)$ & $3(42.85 \%)$ \\
\hline
\end{tabular}

Table 3: lipid profile level

\begin{tabular}{|l|l|l|l|}
\hline Lipid profile & Septic group & Control & p-value \\
\hline Cholesterol $(\mathrm{mg} / \mathrm{dl})$ & $94.1 \pm 24.21$ & $116.23 \pm 16.32$ & $<0.05$ \\
\hline Triglyceride $(\mathrm{mg} / \mathrm{dl})$ & $177.23 \pm 45.32$ & $182.34 \pm 44.01$ & $>0.05$ \\
\hline $\mathrm{HDL}(\mathrm{mg} / \mathrm{dl})$ & $20.56 \pm 10.02$ & $28.23 \pm 6.23$ & $<0.05$ \\
\hline $\mathrm{LDL}(\mathrm{mg} / \mathrm{dl})$ & $61.23 \pm 14.21$ & $75.21 \pm 16.23$ & $<0.05$ \\
\hline
\end{tabular}

Cholesterol, HDL and LDL level difference in septic and control was stastically significant.

\section{Discussion}

This study investigated changes in plasma lipid levels in patients with sepsis, and particularly whether they have prognostic implications. We found markedly lower levels of cholesterol, LDL and HDL on admission and 10 days later with sepsis.

The exact pathophysiological mechanisms underlying hypocholesteraemia in severe illness and sepsis have never been fully understood ${ }^{9}$ Different mechanisms, including dysbalance between synthesis and utilization of plasma lipids, usage of lipids to restore damaged cell membranes, and interaction of cytokines and bacterial toxins with lipids, have been discussed 10

Clinical and experimental studies demonstrated that high circulating levels of cytokines decrease cholesterol levels during severe infection ${ }^{11}$. Antiinflammatory and anti-oxidative properties of HDL were described.

One important mechanism leading to the decrease in HDL is consumption through bacterial substances, particularly lipopolysaccharide (LPS) and other endotoxins. Thus, lipids are used as a scavenger mechanism of host defense because cholesterol and lipoproteins mediate LPS clearance through 
detoxification, forming complexes and neutralizing its toxic effects ${ }^{12}$. In addition, lipoproteins bind a wide variety of enveloped and non-enveloped DNA and RNA viruses and are involved in defense against several parasites. In accordance with these experimental findings, the present study demonstrates that in unselected patients with sepsis, less cholesterol values on admission were seen like some other studies. ${ }^{13,41}$ If confirmed in further studies and combined with other prognostic clinical and laboratory markers, measurement of plasma lipids may allow clinicians to assess the patients with sepsis. The variation during the hospital stay and the correlation of HDL with albumin and Creactive protein suggests that $\mathrm{HDL}$ is a dynamic surrogate marker of systemic infections ${ }^{15}$. Keeping this in mind, physicians should be reminded that measurement of cholesterol values in patients with systemic infections should not be used for cardiovascular risk prediction, since circulating levels of cholesterol, LDL and HDL may be false-low and levels of TG may be false-increased respectively.

\section{Conclusion}

In ICU setting, measurement of cholesterol values has been shown to improve risk prediction, and inclusion of lipid values in clinical risk assessment scores of critically ill patients has been advocated.

\section{References}

1. Levy MM, Fink MP, Marshall JC, Abraham E, Angus D, Cook D, et al. 2001 sccm/esicm/ accp/ats/sis international sepsis definitions conference. Intensive Care Medicine. 2003;29(4):530-38.

2. Carpentier YA, Scruel $O$. Changes in the concentration and composition of plasma lipoproteins during the acute phase response. Current Opinion in Clinical Nutrition \& Metabolic Care. 2002;5(2):15358.

3. Khovidhunkit W, Memon RA, Feingold KR, Grunfeld C. Infection and inflammation induced proatherogenic changes of lipoproteins. Journal of Infectious Diseases. 2000;181(Supplement 3):S462-S72.

4. Lee SH, Park MS, Park BH, Jung WJ, Lee IS, Kim SY, et al. Prognostic implications of serum lipid metabolism over time during sepsis. BioMed Research International. 2015;2015: 8 pages.

5. Nassaji M, Ghorbani R. Plasma lipid levels in patients with acute bacterial infections. Turkish Journal of Medical Sciences. 2012; 42(3):465-69.

6. Khosla SN, Goyle N, Seth RK. Lipid profile in enteric fever. The Journal of the Association of Physicians of India. 1991;39(3):260-62.

7. Alvarez C, Ramos A. Lipids, lipoproteins, and apoproteins in serum during infection. Clinical chemistry. 1986;32(1):142-45

8. Mineo, C., and P. W. Shaul. Role of highdensity lipoprotein and scavenger receptor $B$ type I in the promotion of endothelial repair. Trends Cardiovasc. Med. 2007. 17: 156-161.

9. Takao Kimura, Chihiro Mogi, Hideaki Tomura, Atsushi Kuwabara, Doon-Soon Im, Koichi Sato, Hitoshi Kurose, Masami Murakami ,Fumikazu Okajima,. AntiInflammatory Actions in Endothelial Cells High-Density Lipoprotein-Induced Is Critical for Simvastatin Enhancement of Induction of Scavenger Receptor Class B Type I J Immunol 2008;181;7332- 7340.

10. Barati M, Talebi-Taher M, Golgiri F. Evaluation of diabetes mellitus in patients with sepsis Iranian Journal of Clinical Infectious Diseases 2008;3(4):221-225

11. Giovannini I, Boldrini G, Chiarla C, Giuliante F, Vellone M, Nuzzo G. Pathophysiologic correlates of hypocholesterolemia in critically ill surgical patients. Intensiv Care Med. 1999;25: 748- 51.

12. Gordon BR, Parker TS, Levine DM, Saal SD, Wang JC, Sloan BJ, et al. Relationship of hypolipidemia to cytokine concentrations and outcomes in critically ill surgical patients. Crit Care Med. 2001;29:1563-8.

13. van Leeuwen $H J$, Heezius EC, Dallinga GM, van Strijp JA, Verhoef J, van Kessel KP. Lipoprotein metabolism in patients with 
Pramod Sood et al, International Journal of Medical and Biomedical Studies (IJMBS)

severe sepsis. Crit Care Med. 2003;31:135966.

14. Levine DM, Parker TS, Donnelly TM, Walsh $A$, Rubin AL. In vivo protection against endotoxin by plasma high density lipoprotein. Proc Natl Acad Sci U S A 1993;90:12040-4.
15. Esteve E, Ricart W, Fernandez-Real JM. Dyslipidemia and inflammation: an evolutionary conserved mechanism. Clin Nutr. 2005;24:16-31. 22- Levels $\mathrm{JH}$, Abraham PR, van Barreveld EP, Meijers JC, van Deventer SJ. Distribution and kinetics of lipoprotein-bound lipoteichoic acid. Infect Immun. 2003;71:3280-4. 